\title{
Severe Hypocalcemia After the Administration of Zoledronic Acid for Osteoporotic Fracture
}

\author{
Dohee Kimª, b, c
}

\begin{abstract}
Zoledronic acid is a potent intravenous bisphosphonate used in the treatment of osteoporosis and malignancy-induced hypercalcemia or bone metastasis. Although zoledronic acid generally seems to be safe and well-tolerated, rare but life-threatening nephrotoxicity or hypocalcemia may occur. The majority of cases of hypocalcemia with zoledronic acid have been seen in patients with underlying malignancy and are asymptomatic or mild. Vitamin D deficiency, renal failure, hypoparathyroidism, and hypomagnesemia have been reported as risk factors for hypocalcemia. Here, the author reports a case of severe symptomatic hypocalcemia following the administration of zoledronic acid for the treatment of osteoporotic fracture. This patient also had underlying but unrecognized vitamin D deficiency and chronic kidney disease. Following the administration of calcium and vitamin D, her symptoms improved and calcium levels returned to normal within several days. To avoid serious hypocalcemia with zoledronic acid, calcium and vitamin D status and renal function should be assessed and corrected if appropriate.
\end{abstract}

Keywords: Bisphosphonate; Hypocalcemia; Osteoporosis; Zoledronic acid

\section{Introduction}

Zoledronic acid is a potent intravenous (IV) aminobisphosphonate used in the treatment of osteoporosis, Paget's disease of the bone, and multiple myeloma or bone metastases from solid tumors $[1,2]$. The combination of its high affinity to hydroxya-

\footnotetext{
Manuscript accepted for publication September 08, 2016

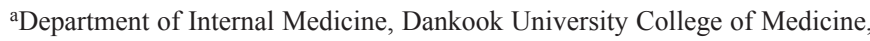
Cheonan 330-714, Korea

bDepartment of Kinesiologic Medical Science, Graduate, Dankook University, Cheonan 330-714, Korea

${ }^{\mathrm{c}}$ Corresponding Author: Dohee Kim, Division of Endocrinology, Department of Internal Medicine, Dankook University College of Medicine, 119, Dandaero, Dongnam-gu, Cheonan-si, Chungnam 330-714, Korea.

Email:dh9070@hanmail.net
}

doi: http://dx.doi.org/10.14740/jmc2646w patite and its potent inhibition of the key osteoclastic enzyme farnesyl pyrophosphate synthase translates into a yearly parenteral treatment regimen for osteoporosis. The parenteral route of administration circumvents the poor adherence associated with oral bisphosphonates and the potential gastrointestinal side effects. Combined with its high efficacy in reducing the risk of vertebral and non-vertebral fractures, zoledronic acid is a reasonable option for elderly patients with comorbidities and those who do not tolerate or absorb oral bisphosphonates $[3,4]$.

Side effects associated with the use of zoledronic acid include a transient and self-limiting acute-phase reaction, in particular during the first administration, mild to moderate hypocalcemia, mild and transient renal impairment, and rare osteonecrosis of the jaw or atypical femur fractures $[3,4]$. The majority of cases of hypocalcemia with zoledronic acid have been seen in cancer patients with bone metastases receiving a higher dosage and were mild or asymptomatic $[5,6]$. Here, the author reports a case of severe symptomatic hypocalcemia following the administration of zoledronic acid for the treatment of osteoporotic fracture.

\section{Case Report}

A 69-year-old woman was referred for workup and treatment of hypocalcemia from the department of neurology. She presented with a tingling sensation all over the body, especially the face, hands and feet, and a feeling like being choked, which had been developing for 18 days after vertebroplasy about 3 weeks ago. She also had paresthesia of the whole body, particularly the face and abdomen, nausea, poor oral intake, and insomnia. She had acute back pain due to a compression fracture on the fourth lumbar spine vertebra and thus received vertebroplasty and neuroplasty at another orthopedic hospital 3 weeks prior to admission. She had no other specific medical diseases, such as diabetes or hypertension, or surgery in her past history, and was non-smoker and non-drinker. Her symptoms, which she had never experienced before, were too severe to maintain daily life at home. She was admitted for workup and treatment in the department of neurology. The patient's clinical details were as follows: $155 \mathrm{~cm}, 57 \mathrm{~kg}$, blood pressure 139/88 mm $\mathrm{Hg}$, pulse rate 80 beats $/ \mathrm{min}$, respiratory rate $20 / \mathrm{min}$, and body temperature $36.6{ }^{\circ} \mathrm{C}$. Her mental state was alert, and she had 
Table 1. Laboratory Profile and Therapy of a Patient With Hypocalcemia After Zoledronic Acid Therapy

\begin{tabular}{|c|c|c|c|c|c|c|c|c|c|c|}
\hline & D0 & D1 & D2 & D3 & D4 & D14 & D24 & D45 & 3 month & 5 months \\
\hline \multicolumn{11}{|l|}{ Serum levels } \\
\hline Calcium $(\mathrm{Ca})(\mathrm{mg} / \mathrm{dL})$ & 3.9 & 3.3 & 4.2 & 5.5 & 7.5 & 9.8 & 8.8 & 8.9 & 8.8 & 9.1 \\
\hline Albumin $(\mathrm{g} / \mathrm{dL})$ & - & 3.3 & 3.4 & 3.2 & 3.4 & 4.0 & 4.1 & 4.2 & 4.4 & 4.2 \\
\hline Corrected $\mathrm{Ca}(\mathrm{mg} / \mathrm{dL})$ & - & 3.9 & 4.7 & 6.1 & 8.0 & 9.8 & 8.7 & 8.7 & 8.5 & 8.9 \\
\hline Ionized $\mathrm{Ca}(\mathrm{mmol} / \mathrm{L})$ & - & 0.46 & - & 0.74 & - & - & - & - & - & - \\
\hline Phosphorus (mg/dL) & 1.3 & 3.1 & 2.4 & - & 2.3 & 1.6 & 2.0 & 2.3 & 2.7 & 2.7 \\
\hline Creatinine (mg/dL) & 1.81 & 1.72 & 1.78 & 1.76 & 1.81 & 2.42 & 2.44 & 2.08 & 2.73 & 2.49 \\
\hline eGFR & 29.5 & 31.3 & 30.0 & 30.4 & 29.5 & 21.1 & 20.9 & 25.1 & 18.3 & 20.4 \\
\hline PTH (pg/mL) & 434.4 & 400.9 & - & - & - & 40.1 & 83.3 & - & - & - \\
\hline $25(\mathrm{OH}) \mathrm{D}(\mathrm{ng} / \mathrm{mL})$ & - & 5.8 & - & - & - & 13.3 & 11.1 & - & - & - \\
\hline $1,25(\mathrm{OH})_{2} \mathrm{D}(\mathrm{pg} / \mathrm{mL})$ & 11.9 & 9.4 & - & - & - & 93.2 & - & - & - & - \\
\hline Magnesium $(\mathrm{mEq} / \mathrm{L})$ & - & 1.0 & - & - & - & 1.5 & - & - & - & - \\
\hline \multicolumn{11}{|l|}{ Replacement } \\
\hline $\mathrm{Ca}$ IV & + & + & + & + & - & - & - & - & - & - \\
\hline $\mathrm{KH}_{2} \mathrm{PO}_{4} \mathrm{IV}$ & + & - & - & - & - & - & - & - & - & - \\
\hline Oral Ca (g/day) & 0.6 & 1.2 & 1.8 & 1.8 & 1.2 & 0.4 & - & - & - & - \\
\hline Oral calcitriol ( $\mu \mathrm{g} /$ day $)$ & - & 0.5 & 0.5 & 0.75 & 0.75 & 0.5 & 0.25 & 0.25 & 0.25 & 0.25 \\
\hline
\end{tabular}

D0 means the day when the patient presented with hypocalcemia and serum calcium was measured at the first time. Ca IV indicates intravenous calcium gluconate therapy, $10 \mathrm{~mL}$ at $10 \%$.

intact motor and sensory and hypoactive deep tendon reflex on neurological examination. She also showed a bilateral falling tendency and shuffled her feet along due to left knee pain when she was walking. Laboratory results were arterial blood $\mathrm{pH}$ 7.4, $\mathrm{PCO}_{2} 24, \mathrm{PO}_{2} 111, \mathrm{HCO}_{3}^{-} 14.9, \mathrm{O}_{2}$ saturation $98 \%$, leukocytes $7,390 / \mu \mathrm{L}$, hemoglobin $11.4 \mathrm{~g} / \mathrm{dL}$, platelets $283,000 / \mu \mathrm{L}$, blood urea nitrogen $16.1 \mathrm{mg} / \mathrm{dL}(6-20)$, serum creatinine 2.02 $\mathrm{mg} / \mathrm{dL}(0.5$ - 0.9), estimated glomerular filtration rate (eGFR) $25.96 \mathrm{~mL} / \mathrm{min} / 1.73 \mathrm{~m}^{2}$, serum sodium $138 \mathrm{mmol} / \mathrm{L}$ (136 - 145), potassium $4.1 \mathrm{mmol} / \mathrm{L}$ (3.5 - 5.1), chloride $104 \mathrm{mmol} / \mathrm{L} \mathrm{(98} \mathrm{-}$ 107), albumin $3.7 \mathrm{~g} / \mathrm{dL}(3.4$ - 4.8), HbA1c 5.3\%, free thyroxine $1.81 \mathrm{ng} / \mathrm{dL}(0.78-1.94)$, and thyroid stimulating hormone $0.2 \mathrm{mIU} / \mathrm{L}(0.25$ - 4.0). Her serum creatinine level had been $1.72 \mathrm{mg} / \mathrm{dL}$ (eGFR $31.25 \mathrm{~mL} / \mathrm{min} / 1.73 \mathrm{~m}^{2}$ ) 20 months prior when it was checked at our hospital for workup as a result of dizziness. Brain magnetic resonance imaging (MRI) showed no focal lesions and abdominal-pelvic computed tomography (CT) and gastrofundoscopy revealed small sized kidneys on both sides with prominent parenchymal wasting, suggesting chronic kidney disease and non-specific findings, respectively. On electrocardiography, the corrected QT interval (532 ms) was prolonged. Additionally, she had serum calcium $3.9 \mathrm{mg} /$ $\mathrm{dL}(8.4$ - 10.4), phosphorus $1.3 \mathrm{mg} / \mathrm{dL}(2.7$ - 4.5), intact parathyroid hormone (PTH) $434.4 \mathrm{pg} / \mathrm{mL}$ (10 - 57), 25-hydroxyvitamin D (25(OH)D) $5.8 \mathrm{ng} / \mathrm{mL}, 1.25$-dihydroxyvitamin D $\left(1,25(\mathrm{OH})_{2} \mathrm{D}\right) 11.94 \mathrm{pg} / \mathrm{mL}(19.6$ - 54.3), and magnesium 1.0 $\mathrm{mEq} / \mathrm{L}(1.3-2.1)$. She had carpal spasms, Chvostek's sign, and Trousseau's sign. Zoledronic acid was injected intravenously on the day after vertebroplasty for the treatment of osteoporotic fracture. She was soon taking IV calcium and phosphorus and then oral calcium and calcitriol replacement. Her symptoms improved slowly while taking oral calcium $1.8 \mathrm{~g}$ /day and calcitriol $0.75 \mu \mathrm{g} /$ day and an infusion of calcium twice daily. The serum corrected calcium levels were $8.0 \mathrm{mg} / \mathrm{dL}$ without IV calcium replacement after 4 days, and she was discharged with oral calcium $1.2 \mathrm{~g} /$ day and calcitriol $0.75 \mu \mathrm{g} /$ day. Ten days after discharge, her serum calcium levels were $9.8 \mathrm{mg} /$ $\mathrm{dL}$, phosphorus $1.6 \mathrm{mg} / \mathrm{dL}$, and creatinine $2.42 \mathrm{mg} / \mathrm{dL}$ (eGFR $\left.21.07 \mathrm{~mL} / \mathrm{min} / 1.73 \mathrm{~m}^{2}\right)$, PTH $40.1 \mathrm{pg} / \mathrm{mL}, 25(\mathrm{OH}) \mathrm{D} 13.3 \mathrm{ng} /$ $\mathrm{mL}, 1,25(\mathrm{OH})_{2} \mathrm{D} 93.19 \mathrm{pg} / \mathrm{mL}$, and magnesium $1.5 \mathrm{mEq} / \mathrm{L}$, and the dose of medication was reduced to oral calcium 400 $\mathrm{mg} /$ day and calcitriol $0.5 \mu \mathrm{g} /$ day. After 10 days, she had no symptoms and serum calcium $8.8 \mathrm{mg} / \mathrm{dL}$, phosphorus $2.0 \mathrm{mg} /$ $\mathrm{dL}$, and creatinine $2.44 \mathrm{mg} / \mathrm{dL}$ (Table 1). She has been taking only calcitriol $0.25 \mu \mathrm{g} /$ day with normal serum calcium levels without a calcium supplement and has been followed up by a nephrologist for chronic kidney disease.

\section{Discussion}

Zoledronic acid represents a highly potent IV aminobisphosphonate that is effective in various benign and malignant metabolic bone diseases [3]. Zoledronic acid has been commonly used because of its high potency and ease of administration [7]. In the osteoporosis setting, its administration by IV infusion once a year virtually eliminates compliance issues and gastrointestinal side effects, thus leading to improved fracture protection and cost effectiveness [4]. Although zoledronic acid is generally well-tolerated, the most common side effects in- 
clude an acute-phase reaction, hypocalcemia, and renal toxicity $[3,4]$. Some of these side effects can be minimized by adequate calcium and vitamin $\mathrm{D}$ supplementation, generous rehydration, and discontinuation of drugs that potentiate renal toxicity, such as diuretics or non-steroidal anti-inflammatory compounds $[3,4,6]$.

The plasma concentrations of zoledronic acid are maximal at the end of the IV infusion, then rapidly decline to less than $10 \%$ in $4 \mathrm{~h}$ and to less than $1 \% 24 \mathrm{~h}$ after the infusion $[4,6]$. About $61 \%$ of the administered dose is taken up rapidly by bone tissue with an increased turnover rate, and is then slowly released back into the circulation. The remaining 39\% is excreted unchanged via glomerular filtration by the kidneys, with a long terminal elimination half-life of $146 \mathrm{~h}[4,6]$. Because zoledronic acid clearance is dependent on the patient's creatinine clearance $(\mathrm{CCr})$, its administration is not recommended in those with a $\mathrm{CCr}<35 \mathrm{~mL} / \mathrm{min}$, although there is no need to adjust the dose in those with $\mathrm{CCr} \geq 35 \mathrm{~mL} / \mathrm{min}$. It is also recommended that the IV infusion time be at least $15 \mathrm{~min}$ for renal safety $[4,6]$. Zoledronic acid does not inhibit the P450 enzymes and has no known drug interactions; however, caution should be exercised in patients on potentially nephrotoxic medications $[4,6]$.

Zoledronic acid potently inhibits osteoclastic bone resorption and reduces the mobilization of calcium from the bones to the circulation [4]. Therefore, its administration may lead to mild secondary hyperparathyroidism as a compensatory mechanism to maintain normocalcemia. Increased PTH prevents hypocalcemia by the renal reabsorption of calcium, the stimulation of osteoclasts to resorb bone, and increased $1,25(\mathrm{OH})_{2} \mathrm{D}$ production leading to increased gastrointestinal absorption of calcium [5]. Patients with vitamin D deficiency, hypoparathyroidism, or renal failure may not be able to correct the hypocalcemia, which then becomes symptomatic $[4$, 5]. It is therefore important to ensure that patients about to be administered zoledronic acid are not vitamin D-deficient and that they have an adequate daily intake of calcium and vitamin D. If there are any concerns, it may be prudent to assay serum 25(OH)D, PTH, calcium, and phosphorus levels. Bisphosphonate-induced hypocalcemia may be avoided or attenuated by the administration of vitamin D and calcium supplements [4]. In addition, because magnesium is required for PTH release, hypomagnesemia may further increase the risk by inhibiting a compensatory increase in PTH secretion [7]. Impaired renal function, vitamin D deficiency, hypoparathyroidism, and hypomagnesemia have known to be the significant risk factors contributing to bisphosphonate-induced hypocalcemia $[6$, $8-10]$. Malnutrition or malabsorption, metastatic cancer, and simultaneous steroid injection have also been reported as risk factors of bisphosphonate-induced hypocalcemia $[5,9]$.

This is a case of severe hypocalcemia after an infusion of zoledronic acid for the treatment of osteoporosis in a patient with coexisting but unrecognized severe vitamin D deficiency and impaired renal function. Secondary hyperparathyroidism with severe hypocalcemia and vitamin D deficiency could not increase $1,25(\mathrm{OH})_{2} \mathrm{D}$ production adequately due to renal failure and severe vitamin $\mathrm{D}$ deficiency, leading to aggravated severe hypocalcemia. Hypophosphatemia by vitamin D deficiency and secondary hyperparathyroidism improved shortly after phosphorus replacement intravenously, and hypomagnesemia also improved spontaneously without replacement after returning to a regular diet. Hypocalcemia in this case was not detected until about 12 days after the development of symptoms. However, serum calcium was not measured at the other hospital or in the emergency room 1 week before admission and for a few days after admission, although the measurement of serum calcium should be routinely performed nowadays. The patient underwent unnecessary brain and abdominal imaging and gastrofundoscopy. Due to the high incidence of vitamin D deficiency, the low accuracy of clinical risk factors to predict vitamin D deficiency, and the generalized measurement of vitamin D status, screening for vitamin D deficiency before the administration of zoledronic acid may be appropriate [10, 11]. It is prudent to measure serum $25(\mathrm{OH}) \mathrm{D}$, calcium, phosphorus, and PTH before starting treatment with zoledronic acid in patients with a high risk of developing symptomatic hypocalcemia. In addition, zoledronic acid should not be administered in patients with a $\mathrm{CCr}<35 \mathrm{~mL} / \mathrm{min}$. Furthermore, high-risk patients should be monitored closely after the initiation of zoledronic acid treatment to detect and correct hypocalcemia and impaired renal function [5].

\section{Conflicts of Interest}

None.

\section{References}

1. Lyles KW, Colon-Emeric CS, Magaziner JS, Adachi JD, Pieper CF, Mautalen C, Hyldstrup L, et al. Zoledronic acid and clinical fractures and mortality after hip fracture. N Engl J Med. 2007;357(18):1799-1809.

2. Costa L, Major PP. Effect of bisphosphonates on pain and quality of life in patients with bone metastases. Nat Clin Pract Oncol. 2009;6(3):163-174.

3. Tsourdi E, Rachner TD, Gruber M, Hamann C, Ziemssen T, Hofbauer LC. Seizures associated with zoledronic acid for osteoporosis. J Clin Endocrinol Metab. 2011;96(7):1955-1959.

4. Hamdy RC. Zoledronic acid: clinical utility and patient considerations in osteoporosis and low bone mass. Drug Des Devel Ther. 2010;4:321-335.

5. Kreutle V, Blum C, Meier C, Past M, Muller B, Schutz P, Borm K. Bisphosphonate induced hypocalcaemia - report of six cases and review of the literature. Swiss Med Wkly. 2014;144:w13979.

6. Do WS, Park JK, Park MI, Kim HS, Kim SH, Lee DH. Bisphosphonate-induced Severe Hypocalcemia - A Case Report. J Bone Metab. 2012;19(2):139-145.

7. Chennuru S, Koduri J, Baumann MA. Risk factors for symptomatic hypocalcaemia complicating treatment with zoledronic acid. Intern Med J. 2008;38(8):635-637.

8. Maalouf NM, Heller HJ, Odvina CV, Kim PJ, Sakhaee K. Bisphosphonate-induced hypocalcemia: report of 3 cases and review of literature. Endocr Pract. 2006;12(1):48-53.

9. Hanamura M, Iwamoto T, Soga N, Sugimura Y, Okuda 
M. Risk factors contributing to the development of hypocalcemia after zoledronic acid administration in patients with bone metastases of solid tumor. Biol Pharm Bull. 2010;33(4):721-724.

10. Epperla N, Pathak R. Hypocalcemia Secondary to Zole- dronate Therapy in a Patient With Low Vitamin D Level. WMJ. 2015;114(4):163-166; quiz 167.

11. Noriega Aldave AP, Jaiswal S. Severe resistant hypocalcemia in multiple myeloma after zoledronic acid administration: a case report. J Med Case Rep. 2014;8:353. 